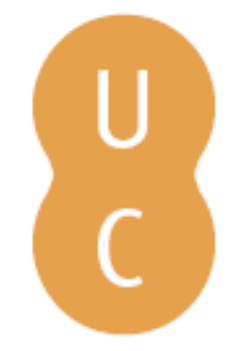

\title{
nommalina
}

\section{Hermenêutica filosófica e mobilidade cultural: H.- G. Gadamer e a relevância das categorias de preconceito e fusão de horizontes e formação}
Autor(es):
Portocarrero, Maria Luísa
Publicado por: Imprensa da Universidade de Coimbra; Annablume
URL
persistente:
URI:http://hdl.handle.net/10316.2/40876
DOI:
DOI:https://doi.org/10.14195/978-989-26-1288-1_16
Accessed : $\quad$ 26-Apr-2023 16:19:41

A navegação consulta e descarregamento dos títulos inseridos nas Bibliotecas Digitais UC Digitalis, UC Pombalina e UC Impactum, pressupõem a aceitação plena e sem reservas dos Termos e Condições de Uso destas Bibliotecas Digitais, disponíveis em https://digitalis.uc.pt/pt-pt/termos.

Conforme exposto nos referidos Termos e Condições de Uso, o descarregamento de títulos de acesso restrito requer uma licença válida de autorização devendo o utilizador aceder ao(s) documento(s) a partir de um endereço de IP da instituição detentora da supramencionada licença.

Ao utilizador é apenas permitido o descarregamento para uso pessoal, pelo que o emprego do(s) título(s) descarregado(s) para outro fim, designadamente comercial, carece de autorização do respetivo autor ou editor da obra.

Na medida em que todas as obras da UC Digitalis se encontram protegidas pelo Código do Direito de Autor e Direitos Conexos e demais legislação aplicável, toda a cópia, parcial ou total, deste documento, nos casos em que é legalmente admitida, deverá conter ou fazer-se acompanhar por este aviso.

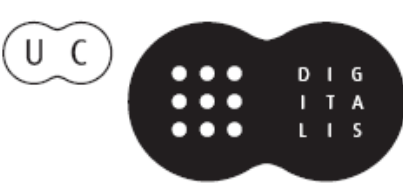




\section{Cosmópolis}

\section{mobilidades culturais às origens do pensamento antigo}

Gabriele Cornelli, Maria do Céu Fialho e Delfim Leão

\section{(coords.)}

IMPRENSA DA UNIVERSIDADE DE COIMBRA 


\title{
Hermenêutica Filosófica e MOBILIdAde CULTURAL: H.- G. GADAMER E A RELEVÂNCIA dAS CATEgorias DE PRECONCEITO E FUSÃO DE HORIZONTES E FORMAÇÃO
} (Philosophical hermeneutics and cultural mobility: H.- G. Gadamer and the relevance of the categories of prejudice and fusion of horizons and of training)

\author{
Maria Luísa Portocarrero (mlp600@gmail.com) \\ Universidade de Coimbra - Centro de Estudos Clássicos e Humanísticos
}

Resumo: O trabalho da hermenêutica, lembra-nos Gadamer, é sempre constituído pela transferência de sentido de um mundo para o outro, nomeadamente do mundo dos deuses para o mundo dos humanos, do mundo de uma língua estranha para o mundo da língua própria, do horizonte da tradição para o do mundo atual. Neste sentido, uma identidade cultural não vive sem a mobilidade, pois não pode sobreviver reduzida a uma única tradição ou linha de significação cultural. Toda a cultura pressupõe o papel emancipador da formação e da interpretação, isto é, parte de pressupostos, é aberta ao outro e, neste sentido, constituída por um processo dialógico de fusão de horizontes. A racionalidade hermenêutica sublinha a necessidade sentida pela compreensão de encontrar o outro e o diferente para se poder realizar, pois é na pluralidade das línguas que se articula a pluralidade dos mundos da vida. O objetivo desta comunicação é tratar das grandes categorias que nos permitem perceber a necessidade e o real sentido da mobilidade cultural para o desenvolvimento do humano.

Palavras-chave: Gadamer; hermenêutica filosófica; identidade e mobilidade cultural; formação; interpretação

Aвstract: The work of hermeneutics, Gadamer reminds us, is always constituted by the transfer of meaning from one world to another, particularly by that from the divine world to the human world, from the world of a foreign language to the world of our own language, from the tradition to our own world. In this sense, a cultural identity cannot live without mobility, therefore, cannot survive as something reduced to a single tradition or cultural context. Every culture presupposes the emancipatory role of education and interpretation, that is, it starts from certain assumptions and is open to the other, and in this sense it consists of a dialogic process of melting horizons. Hermeneutic rationality underlines the subject's need to find the other and the different in order to realize itself, for it is the multiplicity of languages that articulates the plurality of worlds of life. The purpose of this contribution is to address the broad categories that allow us to realize the need and the real meaning of cultural mobility for human development.

KEYwords: Gadamer; philosophical hermeneutics; cultural identity and mobility; education; interpretation

\section{A) A reabilitação do SEntido positivo do PReconceito}

H.- G. Gadamer, o maior representante alemão da Hermenêutica filosófica, 
não pensou explicitamente o problema do multiculturalismo nem mesmo o da mobilidade cultural. Concebeu, no entanto, as grandes categorias que permitem fundamentar antropologicamente estes fenómenos. Foi ele de facto o filósofo do séc. XX que mais se preocupou, logo desde Verdade e método, com a necessidade de contestar o monopólio da subjetividade anónima que governa o mundo desde a modernidade. Necessidade que complementou com toda uma teoria hermenêutica que tem como intuito central promover a formação para o reconhecimento da alteridade do outro.

Contestar o egocentrismo da modernidade, por meio do valor do encontro com o outro, aquele nos traz uma nova visão de mundo ${ }^{1}$, eis o grande objetivo da filosofia hermenêutica de Gadamer. Escopo que se traduz num pensamento dos fundamentos da formação para convivência e para o exercício da pluralidade. Por este facto algumas das suas teses fundamentais são consideradas uma alternativa teórico- existencial ao multiculturalismo.

Vejamos então: discípulo de M. Heidegger com quem diz ter aprendido o essencial, definindo como o seu mestre o Dasein como compreensão e facticidade, Gadamer sabe que a descoberta contemporânea da finitude obriga a reconhecer que, nos dias de hoje, não existe para o homem a possibilidade de um grau zero do pensar. A razão humana sabe-se hoje finita, múltipla, comunicativa e limitada. E isto quer dizer que ela parte sempre de um horizonte concreto e situado de compreensão, isto é, de uma pertença fundamental a uma determinada comunidade humana ou tradição, logo, deve confrontar-se com outros horizontes. Para a racionalidade atual o modelo da lente unívoca da subjetividade tradicional é inadequado. Com efeito, muito antes de nos compreendermos a nós mesmos, de um modo claro, lembra-nos Gadamer, compreendemo-nos, de um modo Pré crítico na Família, na Sociedade civil ou no Estado a que pertencemos. Isto é, somos portadores de uma alteridade que só com os outros podemos esclarecer.

O tema do outro que contesta o nosso egocentrismo e nos sabe apresentar algo que até agora não víamos é o problema básico da filosofia hermenêutica de Gadamer que pode mesmo ser caracterizada como a arte de aprender a não ter sempre razão ${ }^{2}$. A nossa própria razão é já fruto de toda uma conjugação vivida com o outro que existe sempre em correlação connosco. Por isso recorda-nos Gadamer, invertendo o caminho de pensamento que de Fr. Bacon conduziu a Descartes e ao Iluminismo, os preconceitos de um indivíduo constituem muito mais do que os seus juízos claros a realidade histórica do seu modo de ser³.

É preciso, mostra-nos o filósofo. se quisermos fazer justiça ao carácter relacional e finito do ser humano, efectuar uma reabilitação fundamental do

\footnotetext{
${ }^{1}$ Gadamer 1986: 9.

${ }^{2}$ Moratalla 1991.

${ }^{3}$ Gadamer 1986: 295.
} 
conceito de preconceito, depreciado pelo iluminismo e reconhecer que existem preconceitos legítimos. Só os preconceitos, desvalorizados pela Ilustração, permitem hoje ultrapassar o sonho egocêntrico de transparência do conhecimento e fazer justiça ao valor formativo da mobilidade cultural. Só eles permitem, de facto, enquanto tópicos dialéticos do pensar, o acesso sempre dialógico do homem à verdade.

Com efeito enquanto os preconceitos nos dominam não temos consciência da nossa unilateralidade. É o choque com o outro que os traz à tona e nos faz ver os limites do nosso horizonte, levando-nos simultaneamente a realizar o sentido verdadeiramente dialético e hermenêutico da experiência. Isto é, a consciência que experimenta transforma-se com o outro, pois, o novo horizonte entra num processo dialético com o meu por meio do diálogo e cada um dá ao outro a possibilidade de validar ou não os seus pressupostos.

A racionalidade hermenêutica é profundamente dialógica e sublinha com a reabilitação dos pressupostos, a necessidade da auto-compreensão que o homem tem de si de encontrar o outro, o diferente para se realizar.

Gadamer é assim um defensor do diálogo racional e da possibilidade de comunicação entre culturas, horizontes e mundos diferentes. O diálogo que nós somos é o núcleo central da terceira parte de Verdade e método. Nesta obra, aliás, a palavra do outro marca o espaço de experiência da compreensão.

Categoria da relação, o preconceito em Gadamer tem pois um sentido eminentemente dialógico e promotor da mobilidade. Lembra-nos que hoje depois do reconhecimento fenomenológico do corpo, como verdadeiro espaço de experiência do pensar, a compreensão prévia ou efeito do outro em mim, não pode mais ser remetida para o âmbito do preconceito a evitar. A conquista da identidade e autonomia humanas não segue, hoje, a via do esquecimento transcendental e reflexivo do outro. Constrói-se, pelo contrário, aceitando sem subterfúgios a autonomia e crítica do outro.

Compreender e interpretar sempre significaram, aliás, a necessidade de traduzir para o horizonte concreto singular de cada um a mensagem do texto e de fazer claramente entrar em jogo este horizonte. Verter a mensagem do texto para os seus preconceitos no sentido de alcançar um horizonte comum, eis a tarefa do intérprete que é assim questionado pelo horizonte do texto. Se na sua tradução o intérprete não fizer entrar em jogo a sua pré-compreensão, a interpretação não é conseguida. Os preconceitos são categorias operatórias básicas que permitem toda a compreensão. Só a modernidade racionalista lhes deu um sentido pejorativo.

Aqui reside, de facto, a novidade de Gadamer: os preconceitos da razão humana histórica têm, como revela a sua origem jurídica, um carácter dialógico, provisório e processual - e não um conteúdo definitivo - desconhecido pela Ilustração, mas já presente, de um modo muito claro, no seu âmbito de origem: os quadros da jurisprudência latina. Prejuízo, não significa, na sua forma originária, 
o juízo falso das Luzes, mas pertence ao seu sentido a possibilidade de vir a ser valorizado positiva ou negativamente: "Aquele que quer compreender está exposto aos erros de opiniões prévias que não se comprovam nas coisas mesmas. Elaborar os projectos correctos e adequados às coisas que, como projectos são antecipações que primeiro devem confirmar-se "nas coisas", é a tarefa constante da compreensão. Aqui não existe outra 'objectividade' do que a comprovação que obtêm as opiniões prévias ao longo da sua elaboração"4.

Em sentido jurídico aliás (o sentido primitivo da palavra), o termo exprime a ideia de uma antecipação de sentido (o juízo prévio anterior à sentença definitiva) que só em espaço público, isto é, em tribunal pode vir ou não a confirmar-se. A dialéctica do diálogo de preconceitos, que Gadamer herda do procedimento jurisprudencial e de toda a tópica humanista da formação pela Dialéctica e pela Retórica, tem um intuito fundamental: sublinhar, contra o antropocentrismo da razão moderna, a condição dialógica do pensar humano, a sua natureza profundamente dialética e interrogadora. Só no encontro com o outro posso tomar consciência dos meus pressupostos ,aceitando, sem subterfúgios, a autonomia e crítica do outro, construindo com ele um horizonte comum ou fusão de horizontes.

Mas o que significa este conceito?

\section{B) FusÃo de HORIZONTES}

Com esta expressão H.-G. Gadamer, quer caracterizar contra a ideia romântica e historicista de uma distância rígida entre o horizonte cultural do outro e o do intérprete o nexo de compreensão e de diálogo entre perspetivas que caracteriza o procedimento hermenêutico.

Para o filósofo, quem compreende, por exemplo, um texto ou um documento do passado, parte já do efeito histórico exercido por esse mesmo texto ou tradição, sobre a sua situação temporal. Um horizonte é marcado pelos nossos pressupostos, isto é, é marcado por um conjunto particular de crenças, de valores e conceitos com os quais compreendemos o mundo e os outros. Mas o tradicional ponto de vista dos horizontes fechados que limitam as culturas e as épocas históricas, encerando-as, é uma abstração. Ouçamos o filósofo quanto a este assunto: «Poderá dizer-se neste sentido que existem horizontes fechados? Poderemos dizer que o horizonte do nosso presente é algo tão fechado? (....). Tal como cada indivíduo não é nunca indivíduo solitário, pois está sempre entendendo-se com os outros, da mesma maneira o horizonte fechado que cercaria uma cultura é uma abstracção» ${ }^{5}$.

Com efeito, os preconceitos se delimitam horizontes, marcam fronteiras que são simultaneamente espaços de diálogo e de questionamento. Só nos

\footnotetext{
${ }^{4}$ Gadamer 1986272.

${ }^{5}$ Gadamer 1986: 374.
} 
questionamos se o outro realmente nos interpela. A mobilidade histórica da existência humana, diz-nos Gadamer «reside justamente no facto de, apesar dos preconceitos, não haver um vínculo absoluto a uma determinada posição e, neste sentido, também de não haver horizontes realmente fechados. O horizonte é antes algo no qual fazemos o nosso caminho e que connosco caminha (...), também o horizonte do passado, a partir do qual vive toda a vida humana e que está aí segundo a forma de tradição, se encontra em perpétuo movimento». O passado próprio, tal como o alheio, faz parte do horizonte móvel em que vivemos e que nos determina como tradição.

O conhecimento histórico ou literário é, aliás, um bom exemplo de que a compreensão não é nunca uma pura atualização de conteúdos mortos, depositados em obras escritas. Compreender um texto, um fragmento do passado ou de uma outra cultura é, de facto, entendê-lo a partir da questão que ele hoje ainda ele consegue suscitar-nos: é um processo de contínua fusão ou alargamento de horizontes, pelo qual todo o intérprete participa com outros no longo e árduo caminho do sentido.

O encontro de mundos e de religiões ou culturas diferentes no tempo ou espaço transforma-se assim numa questão absolutamente importante.

Com efeito a verdade, que não é já limitada pelo primado do método, é solidária do poder e efeito da palavra e revela o seu sentido através da solicitação que sempre dirige a todo e cada intérprete, que a queira apropriar. Daí, a necessidade sentida por toda a interpretação de se deixar fecundar pela abertura a outros horizontes: porque o homem é finito, só na linguagem, e seu poder dialógico fundamental, as coisas podem realmente alcançar a sua objetividade (idealidade própria). Só aqui deixam de pertencer ao ponto de vista egoísta de cada sujeito particular, para se elevarem à dimensão da referência comummente partilhada. É de facto na linguagem e no seu poder argumentativo ou dialógico que se percebe realmente toda a diferença existente entre o mundo partilhado e o mundo dominado ${ }^{6}$. Compreender é sempre o processo de fusão dos horizontes aparentemente isolados?

Mas é claro que a fusão de horizontes não é nem a empatia de uma individualidade na outra nem uma submissão do outro aos meus próprios padrões; significa sempre a minha ascensão a uma universalidade com o outro. ${ }^{8}$ Para Gadamer é justamente na pluralidade de línguas que se articula a pluralidade dos mundos da vida. Só na linguagem e no seu poder dialógico o mundo pode adquirir a sua objetividade pois só então deixa de coincidir apenas com o meu ponto de vista para se elevar á dimensão do que é universal porque é comum?

\footnotetext{
${ }^{6}$ Gadamer 1986: 405-407.

${ }^{7}$ Gadamer 1986: 311-312.

${ }^{8}$ Gadamer 1986: 310.

${ }^{9}$ Gadamer 1985: 8.
} 
Em conclusão, na perspectiva de Gadamer, a ideia de fusão de horizontes - conduzida deste modo pelo processo dialéctico da palavra - visa revelar-nos toda a diferença que existe entre uma compreensão hermenêutica e uma compreensão totalitária. A objetividade hermenêutica é inseparável das categorias da comunicação e da implicação no sentido e sabe que o encontro ou fusão de horizontes distintos não é nunca equivalente ao fenómeno da mediação total. Sempre acontecerá em todo o processo de interpretação, diz-nos o filósofo, que a linha de sentido que se revela no decurso da leitura acaba necessariamente numa indeterminação aberta. O leitor deve reconhecer que gerações futuras e culturas diferentes compreenderão de um modo novo o que ele leu neste texto.

\section{C) Formação}

O outro conceito fundamental da hermenêutica de Gadamer que permite fazer plena justiça à mobilidade cultural, fundando-a antopologicamente é o conceito de formação que Gadamer recebe do Humanismo. O filósofo começa as suas reflexões sobre a relação entre a problemática hermenêutica e a questão das humanidades por meio de uma reabilitação dos quatro conceitos fundamentais do humanismo: formação, senso-comum, capacidade de juízo e gosto (...) os grandes esquecidos da hermenêutica metodológica moderna. $\mathrm{O}$ conceito de formação que vamos aqui abordar é tratado em Verdade e método quase como um existencial fundamental do ser humano, como aquilo que lhe permite elevar-se à humanidade, enquanto ser marcado justamente pela mobilidade cultural. Daí a sua importância fundamental.

A origem da palavra formação diz-nos Gadamer encontra-se na mística medieval, na sua sobrevivência na mística do barroco e espiritualização religiosamente tratada pelo "Messias de Klopstock"10. Há que não esquecer ainda no século XVIII Herder que a caracterizou como a elevação à humanidade. Também a religião instruída do séc. XIX conservou o sentido desta palavra estabelecendo o actual conceito de formação.

O filósofo procura, com as suas reflexões, mostrar, em primeiro lugar, que o sentido do conceito de formação excede a sua habitual ligação com o conceito de cultura, baseada do ponto de vista antropológico na ideia de um aperfeiçoamento de faculdades. Com a formação, lembra Gadamer, não pretendemos referir a ideia de cultura, já que esta parece caracterizar mais o resultado da formação do

10 «Wenden wir uns dem Begriff der Bildung $\mathrm{zu}$, dessen Bedeutung für die Geisteswissenschaften wir hervorgehoben haben, so sind wir in einer glücklichen Lage. Hier laßt sich aus einer vorliegenden Untersuchung die Geschichte des Wortes gut überschauen: sein Ursprung in der mittelalterlichen Mystik, sein Weiterleben in der Mystik des Barock, seine religiös begründete Spiritualisierung duch Klopstocks 'Messias', die das ganze Zeitalter ergreift, und schließlich Herders grunlegende Bestimmung Als 'Emporbildung zur Humanität.» (Gadamer 1986: 15-16). 
que a ideia dinâmica de processo ou viagem interior, própria da temporalidade do ser humano: «No fundo, a formação não pode ser meta, não pode ser desejada como tal a não ser na temática reflectida do educador. É precisamente nesse aspecto que o conceito de formação ultrapassa o mero cultivo de aptidões pré-existentes, do qual ele deriva (....).Na formação, pelo contrário, pode também ser inteiramente assimilado o que e aquilo através do qual alguém será instruído. Neste sentido, tudo o que ela assimila, transforma o homem e nele desabrocha. $\mathrm{Na}$ formação aquilo que foi assimilado não é um meio que perdeu a sua função. Pelo contrário nada desaparece na formação adquirida, tudo é preservado. A formação é um conceito genuinamente histórico, e é justamente o carácter histórico da preservação o que importa para a compreensão das ciências do espírito» ${ }^{11}$.

Para Gadamer a formação não é um resultado que pode ser activado, mas um processo histórico interior de transformação e conformação do si, que está por isso em constante desenvolvimento e progressão.

É Hegel quem Gadamer mais valoriza na história do conceito de formação, pois foi ele quem o tratou de forma clara, vendo que a Filosofia tem na formação a sua própria condição de possibilidade. $\mathrm{O}$ mesmo acontece às Ciências do Espírito, sublinha o filósofo, pois o ser do espírito está intimamente ligado à formação. Para Hegel o que caracteriza o humano é a ruptura com o imediato e natural, dada a sua natureza também espiritual e racional. Porque o ser humano não é por natureza o que deve ser, precisa de formação. O que Hegel considera ser a essência geral da formação é a elevação à universalidade; aquele que se abandona à sua particularidade é um inculto ${ }^{12}$.

Assim é característico da formação o sacrifício da particularidade e uma elevação à universalidade que permita a reconciliação de si mesmo no ser do outro. Segundo Hegel, isto torna-se claro na formação teórica: esta leva-nos mais além do que sabemos e experimentamos directamente. Reconhecer no estranho o próprio, tornando-o familiar é segundo Hegel, o movimento fundamental do espírito cujo modo de ser é justamente o retorno a si a partir do outro ${ }^{13}$. Não é a alienação no outro, mas pelo contrário, o retorno a si o que constitui a essência da formação. Embora Hegel não pensasse ainda a mobilidade cultural, podemos ver nesta valorização que dele faz Gadamer, pensador do diálogo de horizontes, um incitamento à sua promoção. A formação, diz Gadamer, não

${ }^{11}$ Gadamer 1986: 17.

${ }^{12}$ «Bildung als Erhebung zur Allgemeinheit ist also eine menschliche Aufgabe. Sieverlangt Aufopferung der Besondderheit für das Allgemeine. Aufopferung der Besonderheit heißt aber negative: Hemmung der Begierde und damit Freiheit vom Gegenstand derselben und Freiheit für seine Gegenständlichkeit.Hier ergänzen die Deduktionen der phänomenologischen Dialektik das in der 'Propädeutik'Ausgeführte.In der Phänomenologie des Geistes entwickelt Hegel die Genese eines wirklich 'an und für sich ‘feien Selbewußtseins und zeigt daß es das Wesen der Arbeit ist, das Ding zu bilden statt es zu verzehren» (Gadamer 1986: 18).

${ }^{13}$ Gadamer 1986: 19. 
deve ver-se apenas «como o processo que realiza a ascensão histórica do espírito ao universal, mas também como o elemento no interior do qual se move quem deste modo se formou» ${ }^{14}$.

Indo para além de Hegel e perguntando pela natureza deste elemento «no qual se move quem...se formou», Gadamer mostra a sua insatisfação relativamente ao absolutismo em que caiu Hegel e refere-se a Helmoltz. Diz-nos então «que o que Helmoltz descreve como forma de trabalho das ciências do espírito e em particular o que ele chama de sensibilidade e tacto artístico pressupóe de facto este elemento da formação no interior do qual é dada ao espírito uma mobilidade especialmente livre» ${ }^{15}$. Pelo tacto entende-se uma determinada sensibilidade e capacidade de perceção de situações bem como o comportamento dentro delas quando não temos, no que a elas diz respeito nenhum saber derivado de princípios gerais.

O tacto, tão valorizado por Gadamer com núcleo da formação, parece-nos ser realmente o que importa quando se trata, como na mobilidade cultural, da transferência de um horizonte para um outro pois, como nos diz Gadamer, «ele ajuda a manter a distância, evita o chocante, a aproximação excessiva e a violação da esfera íntima da pessoa» ${ }^{16}$. O tacto implica uma forma de sensibilidade que é capaz de extrair conhecimento a partir da própria situação concreta e sabe lidar com ela. $\mathrm{O}$ tacto atesta-se em situações em que justamente surge a diferença e é uma forma especial de abertura a essa mesma diferença ${ }^{17}$. Pressupõe um sentido do estético e do histórico ${ }^{18}$. E isto é precisamente, diz-nos Gadamer, «o que seguindo Hegel destacamos como característica geral da formação, este manter-se aberto para o outro, para pontos de vista mais gerais e diferentes. A formação compreende um sentido geral da medida e da distância relativamente a si mesmo e implica pois o saber elevar-se acima de si mesmo em direcção à universalidade. No entanto os pontos de vista gerais aos quais se mantém aberta a pessoa formada não são constringentes, mas possíveis.

Um sentido universal e comunitário - esta é de facto uma formulação para a essência da formação, em que se percebe o eco de um ampla conexão histórica» ${ }^{19}$. Percebemos pois como a nossa essência profundamente hermenêutica, quando

${ }^{14}$ Gadamer 1986: 19.

${ }^{15}$ Gadamer 1986: 20-21.

${ }^{16}$ Gadamer 1986: 20-21.

17 «Nun ist der Takt, von dem Helmholtz spricht, nicht mit diesem sittlichen und Umgangsphänomen einfach identisch. Aber es gibt hier ein wesenhaft Gemeisames. Denn auch der in dem Geisteswissenschaftwirksame Takt erschöpft sich nicht darin, ein Gefühl und unbewußt zu sein, sondern ist eine Erkenntnisweise und eine Seinsweise zugleich.Das la $\beta$ t sich aus der oben durchgeführten Analyse des Begriffs der Bildung genauer sehen.Was Helmholtz Takt nennt, sclie $\beta$ t Bildung ein und ist eine Funktion sowohl ästhetischer wie historischer Bildung» (Gadamer 1986: 22).

${ }^{18}$ Gadamer 1986: 20-21.

${ }^{19}$ Gadamer 1986: 23. 
Hermenêutica filosófica e mobilidade cultural:

H.- G. Gadamer e a relevância das categorias de preconceito e fusão de horizontes e formação

formada, nos permite o tacto tão necessário à mobilidade cultural como forma de constituição da nossa própria identidade.

Reconhecermo-nos num sentido comum não puramente teorético mas practico- político, tal é o escopo da última fase do pensamento hermenêutico de Gadamer que tanto insiste na ideia de que é preciso uma formação para saber ouvir, reconhecer os seus pressupostos e e poder dialogar.

\section{Conclusão}

A valorização gadameriana da formação como núcleo primordial da cultura própria das Humanidades é hoje absolutamente central, se queremos reconhecer o valor da mobilidade cultural e exercer o acolhimento do diferente. Não pode haver verdadeiro reconhecimento do outro horizonte se não existir formação que nos faça perceber que, porque somos finitos, partimos sempre de preconceitos ou pré-compreensões, que condicionam o nosso acesso ao sentido, dado que nos remetem para um enraizamento simbólico diferente de outros. Só questionados pelos outros tomamos consciência nossa particularidade imediata podendo assim abrir-nos a outras perspetivas, caminhando com o outro em direcção a um entrelaçamento de horizontes ou senso-comum ético e político que estabeleça compromissos mas não anule a riqueza das diferentes convicções.

Por isso, valorizámos com Gadamer o tacto no caminho da formação que nos é traçada pela sua reabilitação do sentido positivo do preconceito e pela sua proposta de uma fusão de horizontes, que conduza a um sentido comum, mais verosímil do que constringente. A formação necessária à mobilidade cultural é humanística e não técnica ou especializada, pressupõe o desenvolvimento da nossa capacidade para sentir situações diferentes da nossa e para nos colocarmos nelas e ainda a possibilidade de aprender a não ter sempre razão. Estas capacidades, lembra-nos Gadamer, não possuem qualquer tipo de princípios universais que lhes permitam exercer-se, com eficácia e destreza técnica, nem qualquer conhecimento sedimentado que possa ensinar-se. Pelo contrário, elas são hermenêuticas, exercem-se na própria situação concreta e exigem a longa frequentação dos universais verosímeis da condição humana que nos são transmitidos pela hermenêutica da literatura histórica e de ficção.

A frequentação hermenêutica dos clássicos e da tradição permite-nos desenvolver uma capacidade de juízo que, tal como o tacto, foca as coisas singulares pela óptica dos pontos de vista justos correctos e sãos, isto é, aplica pontos de vista gerais sem nunca sacrificar o singular. Ela cultiva o gosto enquanto conceito de origem mais moral do que estético que nos remete diretamente para uma forma de raciocínio diferente do empresarial, pelo qual hoje somos governados. A racionalidade da phronesis aristotélica, que Gadamer recupera como modelo para a Hermenêutica filosófica, sabe pois jogar com a mobilidade cultural dado, que apela à prudência na aplicação ética, isto é, à capacidade de deliberar antes 
da aplicação dos costumes, que considera nunca serem dados como um todo acabado ou entendidos normativamente de maneira unívoca.

Tal como a phronesis, o gosto, um dos quatros conceitos do Humanismo que Gadamer recupera no seu ideal hermenêutico de formação, mediante a consciencialização de preconceitos e da fusão dialógica de horizontes, sabe que os costumes não podem ser aplicados automaticamente mas precisam de um juízo hermenêutico para avaliar os casos concretos de forma correta.

Dos quatro conceitos do Humanismo, formação, sentido comum, capacidade de juízo e gosto, valorizámos mais a recuperação gadameriana do primeiro, uma vez que começámos este texto pela fundamentação onto-antropológica que o filósofo faz da necessidade que tem o sujeito de aprender a perceber que o outro também pode ter razão. 
Hermenêutica filosófica e mobilidade cultural:

H.- G. Gadamer e a relevância das categorias de preconceito e fusão de horizontes e formação

\section{Bibliografia}

Gadamer, H.-G. (1986), Hermeneutik 2. Wabrheit und Method 2. Gesammelte Werke 2. Tübingen.

Gadamer, H.- G. (1986), Wabrheit und Methode I. Gesammelte Werke I. Grundzüge einer philosophischen Hermeneutik. Tübingen.

Gadamer, H. -G. (1985), Gesammelte Werke. Griechische Philosophie II. Tübingen.

Moratalla , A. (1991), El arte de poder no ter razón. La hermenéutica dialógica de H.- G. Gadamer. Salamanca. 